\title{
Prioritisation to Manage the Millennium Information Systems Problem
}

\author{
Ashraf W. Labib \\ Mechanical Engineering Department, Manufacturing Division, \\ University of Manchester Institute of Science and Technology (UMIST), \\ UK \\ Email: ashraf.labib@umist.ac.uk
}

\begin{abstract}
The prevailing disciplinary in dealing with the year 2000 computer problem tends to be a prioritisation perspective, which is the issue of this paper. However, the Year 2000 computing problem is considered a multi-disciplinary problem as it concerns fields of information systems, maintenance, decision making, and crisis and risk management as well. This millennium problem is increasingly critical yet still it seems there is no unified approach that considers multiple criteria in a systematic approach. The paper analyses the process of formulating and evaluating an appropriate strategy using Multiple Criteria Decision-Making (MCDM), based on the Analytic Hierarchy Process (AHP), in order to deal with the millennium problem. The proposed methodology is developed to systematise the decision process. The model used was constructed to provide a generic framework for the formulation of appropriate millennium problem solving strategy.
\end{abstract}

Keywords: MCDM, AHP, Millennium Problem, Maintenance

\section{INTRODUCTION}

The background of the year 2000 problem originated in the 1960's when computer programmers used only two digits to store the year part of the date. This was to save space, which was then expensive. Consequently, any clock embedded in a computer can be affected by the Year 2000 problem. Computers rely on three clocks for their time and date to function correctly. The first clock is Real Time Clock "RTC", powered by the back-up battery, stores the two-digit year. The century number (i.e. 19 or 20) is also operated by the RTC but stored separately. The second clock, called "the BIOS clock" (Basic Input Output System), records the time elapsed from when the computer was switched on and gets its date and time from the RTC. The third clock is in the computer's operating system software and is displayed on screen. This gets its date and time from the BIOS clock.

It has been estimated that the Millennium computer crisis will cost the European Commission $£ 750 \mathrm{bn}$ and threatening lives and businesses. However, the overall level of actual preparation appears to be insufficient despite the substantial risk to companies and individuals. At company level, the extent of the problem has been identified to affect personal computers, programmable logic controllers (PLCs), Computer Numerical Controllers (CNCs), production processes, robot controllers, orders, mailings, invoices, security systems, and the list goes on. On the other hand, individuals, and retailers might face big problems with respect to damage to personal and financial records, the miscalculation of transactions, bank accounts, mortgages, and salary payment, along with air-traffic control computers, intensive care units, and telephone systems.

In short, this problem will bring chaos - unless dealt with as a highest priority concern at board level. It matches the saying of "Death by a thousand stinging bees". This is due to the fact that the magnitude of what seems to be a small problem (bee sting) might propagate causing catastrophe (death) by a variety of breakdowns, malfunctions, and errors to the extent that issues of globalisation and integration will be considered a curse rather than a blessing during and possibly beyond Year 2000 .

The problem is further complicated by the fact that the number of experts with specialist knowledge is limited, and they are already much in demand. These experts are bound to become more expensive as demand for their services outstrips supply'. 
The Year 2000 computing problem is considered a multi-disciplinary problem, and current research in other areas can be applied to address this issue. In the field of maintenance, literature concerning intelligent decision-making can be found in ${ }^{2,3,4,5,67,7,9}$. Also, in the field of crisis and risk management, the works of $1,10,1,12,13$ have addressed the millennium problem. However, there is no unified approach that considers multiple criteria in a systematic approach and suggests a systematic method for resource allocation.

In order to be more specific, the methodology in this paper is applied to a specific issue of major importance, namely to formulating a strategy for a manufacturing company to deal with the millennium problem. An actual validation of a simplified version of the model with different decision makers in a leading medium size automotive manufacturing company was carried out to test the performance of a technique called the Analytic Hierarchy Process (AHP).

The structure of this paper is as follows: The next section includes development of the hierarchical model for the AHP methodology in order to analyse decisions regarding the millennium strategies. The following section identifies criticality measures and means of identifying their priorities, as well as the impact of the risk involved. This is followed by a description of the priority derivation for the various options considered using a case study as an example, followed by a section about sensitivity analysis. This is then followed by the application of resource allocation. The final section provides a summary and conclusions.

\section{STRUCTURE OF THE HIERARCHY (MODEL)}

Before delving into the formulation of the model, a number of points are worth mentioning with regard to formulation of hierarchies as a guideline. Decision applications of the AHP are carried out in two phases: hierarchic design and evaluation. In this section, the hierarchic design phase is considered. The design of hierarchies requires experience and knowledge of the problem area.

As a general rule of thumb, according to ${ }^{14}$, the hierarchy is developed from the general (upper levels) to the particular (bottom levels) or from the uncertain or uncontrollable (upper levels) to the more certain or controllable (bottom levels). A useful criterion to check the validity of a hierarchy is to determine if the elements of an upper level can be used as common attributes to compare the elements in the level immediately below with each other. According to ${ }^{15}$, a valuable observation about the hierarchical approach to problem solving is that the functional representation of a system may differ from person to person, but people tend to agree on the bottom level of alternative actions to be taken and the level above it. In constructing a hierarchy upwards, it is particularly helpful to ask: can these elements be compared with respect to each element in the level above? Finally, it appears that a logically constructed hierarchy is a by-product of the entire AHP approach. In other words, AHP is not only a problem-solving tool, but also a modelling tool of the problem concerned.

Using the goal of deciding what action to take for the Year 2000 problem, a hierarchy (see Figure 1) is developed. Following the apex of the hierarchy, the first level of the hierarchy deals with the perceived risk assessment scenarios. The second level identifies the plants, or systems, to be considered. The last level of the hierarchy involves the specific recommended actions. The following discussion deals with the members of each one of the levels of this hierarchy in more detail. 




Figure 1 Hierarchy of the Year 2000 problem

\section{RISK ASSESSMENT OF PRIORITIES AND IMPACT}

This section deals with assigning criticality prioritisation of risk involved. The importance of this step is that it will lead to the choice of initial test candidates. The first step is to assess the importance of each system, and its possibility to fail.

\section{Criticality and Impact Scenarios}

The first level of the hierarchy contains the criticality and impact scenarios. Criticality and impact scenarios have two basic composites:

i) Importance to business operations which is the degree of disruption to running the business.

ii) Likelihood to fail in Year 2000 based on tests, vendors, or experience.

Table 1 Criticality (importance to business operations)

\begin{tabular}{|l|l|}
\hline $\begin{array}{c}\text { Importance to } \\
\text { Business Operations } \\
\text { (Criticality) }\end{array}$ & \multicolumn{1}{|c|}{ From management and investigation team } \\
\hline Critical & Immediate disruption or impact on operations. Direct production. \\
\hline Not Critical & $\begin{array}{l}\text { System will not directly affect operations, but prolonged loss of these systems } \\
\text { will result in inconveniences. }\end{array}$ \\
\hline
\end{tabular}

Table 2 Status (likelihood to fail)

\section{Likelihood to fail 1 From Vendor input / previous testing / plant expertise and inspection}




\begin{tabular}{|l|l|}
\hline \multicolumn{1}{|c|}{ (Status) } & \\
\hline High Likelihood & System will almost definitely fail due to a year 2000 issue \\
\hline Low Likelihood & System probably will not fail year 2000 testing. \\
\hline
\end{tabular}

These composites form different operating scenarios that can be classified as follows:

Scenario 1: Critical System with Low Likelihood to fail (C-LL).

Scenario 2: Critical System with High Likelihood to fail (C-HL).

Scenario 3: Non Critical System with Low Likelihood to fail (NC-LL).

Scenario 4: Non Critical System with High Likelihood to fail (NC-HL).

Naturally, additional or different scenarios may be identified depending on the specific environment faced by a particular company.

\section{Systems Level}

After establishing business risk priority of all systems, management select the initial pool of systems for which Year 2000 behaviour needs to be determined. A list of final test candidates is developed, and accordingly a test plan can be scheduled.

The aim of this exercise is to present a methodology and a generic framework rather than a specific model. This shows that the concept of hierarchies is stable and flexible; stable in that small changes have small effect and flexible in that additions to a well-structured hierarchy do not disrupt the performance.

\section{Options (level 4)}

Finally, in any hierarchy, one usually considers the specific options, or strategies, that are applicable in formulating and implementing a Year 2000 strategy. Available options can be categorised in terms of time, effort, and money into: Retain / Retire / Restore / Replace, or the 4 Rs for short. These 4 Rs vary in their cost of implementation since retaining involves the least cost whereas, restoring and replacing involves higher cost.

\section{A DETAILED ANALYSIS THROUGH A CASE STUDY}

Decision applications of the AHP are carried out in two phases: hierarchic design and evaluation. In the previous section, the hierarchic design phase was considered. In this section the second phase; namely the evaluation phase is considered. In this case study it should be emphasised that the evaluations given are specific to a certain company, and given certain conditions, and should not be considered as a generic model. The first step is to assess the relative importance of the four scenarios (see Figure 1). These scenarios can be assessed to consider the most important scenario, based on prevailing conditions. In this case it will usually be the ones involving critical systems.

The judgement reveals that the more important scenarios are those involving a critical system, with the most important being the one with high likelihood to fail. The evaluation is done through a pair-wise comparison by asking: "Which of the following two scenarios is most important to solve with respect to a certain company ?". Table (3) summarises the answers to this question. The priority column in Table (3) suggests that the scenario labelled "Critical, high likelihood to fail" is dominant in shaping the Year 2000 strategy for this particular company with a priority of 0.536 , "Critical with low likelihood to fail" has a priority of 0.194, "Non critical, high likelihood to fail" has a priority of 0.177 , and "Non critical, low likelihood to fail" has a priority of 0.093 . This outcome reflects the fact that criticality is a dominating factor, and that the high likelihood to fail is of a major concern. 
Table 3 Importance of scenarios

\begin{tabular}{|l|l|l|l|l|c|}
$\begin{array}{l}\text { Objective: } \\
\begin{array}{l}\text { Solve Year } \\
\text { 2000 Problem }\end{array}\end{array}$ & $\begin{array}{l}\text { C-LL } \\
\text { Critical } \\
\text { System with } \\
\text { Low } \\
\text { Likelihood to } \\
\text { fail }\end{array}$ & $\begin{array}{l}\text { C-HL } \\
\text { Critical } \\
\text { System with } \\
\text { High } \\
\text { Likelihood to } \\
\text { fail }\end{array}$ & $\begin{array}{l}\text { NC-LL } \\
\text { Non Critical } \\
\text { System with } \\
\text { Low } \\
\text { Likelihood to } \\
\text { fail }\end{array}$ & $\begin{array}{l}\text { NC-HL } \\
\text { Non Critical } \\
\text { System with } \\
\text { ligh } \\
\text { Likelihood to } \\
\text { fail }\end{array}$ & Importance \\
\hline C-LL & 1 & $1 / 3$ & 3 & 1 & 0.194 \\
\hline C-HL & 3 & 1 & 5 & 3 & 0.536 \\
\hline NC-LL & $1 / 3$ & $1 / 5$ & 1 & $1 / 3$ & 0.093 \\
\hline NC-HL & 1 & $1 / 3$ & 3 & 1 & 0.177 \\
\hline
\end{tabular}

In the next step the systems level of the hierarchy is considered. The analysis is based on the relative strength and influence of each system in shaping and directing the appropriate strategy. One approach is to assess their relative importance based on criteria including for example their cost, influence, reliability, etc. These criteria can be considered as a separate level below the systems level in a separate hierarchy. Another approach is to consider their influence with respect to the upper level in the hierarchy as in Figure (1). If the case of "criticality" is considered, some systems will score high in their comparisons, while in the case of "likelihood to fail" the emphasis will be on other systems. The next step is concerned with finding the priorities of the various systems under each of the four scenarios.

In this case study, the short listing exercise has identified three systems: A, B, and C. System A is an AGV (Automatic Guided Vehicle) system that is vital to the company because it is used for material handling of raw material, work in process, and finished goods across the factory. Hence system A is considered critical. However, System A was developed in the early eighties and consists of $80286 \mathrm{~s}$ microprocessors that are likely to fail in the year 2000 . Hence, system A has a high likelihood of failure. Therefore, system A tends to be belonging to the category of (C-HL).

System B is a new Robot that is controlled by a Pentium processor and hence it has a low likelihood of failure, and it is considered critical to the business as it performs an automatic dangerous operation that cannot be substituted manually. Therefore, system B is considered (C-LL).

System $\mathrm{C}$ is a climatic chamber that speeds the process of drying the product. Its malfunction can bring inconvenience to the operation of the company as it will slow the drying process. It is an old chamber and the clock in its processor displays the date in 2 digits only, and hence its likelihood of failure is relatively high. Hence, system $\mathrm{C}$ tends to belong to the category of (NC-HL).

In assessing, for example, the priorities of the systems with respect to "Critical System with High Likelihood to fail $(C-L L)$ ", the following comparison matrix was obtained as shown in Table (4).

Table 4 Priorities of Systems Level (Level 2) with respect to Scenario 1 (Level 1)

\begin{tabular}{|l|l|l|l|l|}
\cline { 2 - 5 } $\begin{array}{l}\text { Objective: } \\
\text { Scenario 1 (C- }\end{array}$ & System A & System B & System C & $\begin{array}{l}\text { Relative } \\
\text { Likelihood }\end{array}$ \\
\hline System A & 1 & 4 & 7 & 0.71 \\
\hline System B & $1 / 4$ & 1 & 3 & 0.21 \\
\hline System C & $1 / 7$ & $1 / 3$ & 1 & 0.08 \\
\hline
\end{tabular}


Continuing in the same fashion, the priorities of each objective under each scenario were derived; as shown in Table (5). The results demonstrate, for example, that the importance of the system $A$ is significant during critical scenarios, while the importance of the system $C$ is significant during high likelihood to fail scenarios.

Table 5 Local priorities of Level 2 relative to Level 1

\begin{tabular}{|l|l|l|l|l|}
\cline { 2 - 5 } & $\begin{array}{l}\text { C-HL } \\
\text { Critical System } \\
\text { with High } \\
\text { Likelihood to fail }\end{array}$ & $\begin{array}{l}\text { C-LL } \\
\text { Critical System } \\
\text { with Low } \\
\text { Likelihood to fail }\end{array}$ & $\begin{array}{l}\text { NC-HL } \\
\text { Non Critical } \\
\text { System with } \\
\text { High Likelihood } \\
\text { to fail }\end{array}$ & $\begin{array}{l}\text { NC-LL } \\
\text { Non Critical } \\
\text { System with } \\
\text { Low Likelihood } \\
\text { to fail }\end{array}$ \\
\hline System A & 0.71 & 0.35 & 0.18 & 0.14 \\
\hline System B & 0.21 & 0.56 & 0.11 & 0.24 \\
\hline System C & 0.08 & 0.09 & 0.71 & 0.62 \\
\hline Consistency & 0.03 & 0.05 & 0.05 & 0.02 \\
\hline
\end{tabular}

To derive the global priorities of the systems (i.e., how important these systems are to the overall goal and not just to each scenario) one must weight their relative (local) priorities (Table 3 ) by the priorities (likelihood) of the scenarios themselves (Table 5); this yields a vector (Table 6).

Table 6 Global priorities of Systems

\begin{tabular}{|c|c|}
\hline Systems & Priorities \\
\hline System A & 0.493 \\
\hline System B & 0.263 \\
\hline System C & 0.244 \\
\hline
\end{tabular}

When dealing with different systems, if no consensus is reached, then a geometric mean can be used as suggested by Saaty ${ }^{15}$ to average the judgements. This completes the prioritisation of the first two levels, namely that of the scenarios and the systems. To proceed to the last level and for sake of brevity, the priorities of different systems when considering the scenario of "Critical System with High Likelihood to fail (C-HL)" are presented in Table (7).

Table 7 Local assessment of different system' objectives for the scenario of Critical With High Likelihood to Fail (C-HL)

\begin{tabular}{|l|l|l|l|l|}
\cline { 2 - 5 }$(\boldsymbol{C}-\boldsymbol{H L})$ & Retain & Retire & Restore & Replace \\
\hline System A & 0.047 & 0.163 & 0.395 & 0.395 \\
\hline System B & 0.609 & 0.124 & 0.114 & 0.152 \\
\hline System C & 0.110 & 0.418 & 0.250 & 0.223 \\
\hline
\end{tabular}

Note that the priority figures of each system in Table (7) are in the form of percentages, and hence the summations across the rows add up to unity, or $100 \%$. As shown in Table (7), when considering criticality and high likelihood to fail, System A should be either restored or replaced. Whereas, System $\mathrm{B}$ can be retained and finally, System $\mathrm{C}$ should be retired. The judgements are based on the information provided in Table (3). Note that although this information was given in a qualitative format, it was quite easy to transfer it into the model. This shows the power of AHP in being able to deal with information of a non-quantitative structure. The local priorities are now converted into global priorities. One weights the local priorities of the options by the global priorities of the objectives and sums across all objectives; this yields Table (8) showing the global priorities of options.

Table 8 Global priorities of Options (Strategies)

\begin{tabular}{|c|c|}
\hline Table 8 Global priorities of Options (Strategies) & Priorities \\
\hline Options & 0.270 \\
\hline Restore & $\mathbf{0 . 2 6 3}$ \\
\hline Replace & $\mathbf{0 . 2 4 8}$ \\
\hline Retire & $\mathbf{0 . 2 1 8}$ \\
\hline Retain &
\end{tabular}




\section{Consistency Ratio (CR) $=0.06$}

The global priorities of the actions shown above represent the overall desirability of those actions in satisfying the various systems under the four scenarios of criticality and likelihood to fail. Note that choosing the most appropriate strategy can either be based on the decision 'one out of many', or on a 'portfolio' type of decision where a certain budget is allocated and all strategies are implemented according to their relative priority. Although restore and replace actions were the most beneficial options, the net outcome can be different if one considers their accompanied cost and risk. In future research, the intention is to take into consideration benefit / cost, and risk analysis.

\section{SUMMARY AND CONCLUSION}

The main conclusion of this research work is that applying multiple criteria decision making through using AHP, to formulate a strategy for the millennium, has proved to be a comprehensive, practical, and powerful tool: a simple tool that can solve complex problems. The requirements of appropriateness in terms of flexibility, systemisation, structure, and ability to deal with non-quantifiable and multiple objectives, have all been met by using the AHP as a methodology for formulating a strategy for the millennium problem using Expert Choice ${ }^{18}$ - a software implementing AHP. Since the hierarchy usually starts from the general (top level) to the specific (bottom level), it is most likely that the focus and the first levels of the hierarchy can be considered generic for any company. However, the bottom levels of the hierarchy, those that include systems, and alternative strategies, may be adapted according to the specific nature of a company.

\section{Acknowledgements:}

The author would like to express his gratitude to EPSRC for funding this work under grant number GR/M74641.

\section{References}

1. Keogh J, "Solving the Year 2000 Problem", Academic Press, London, UK. 1997.

2. Labib, A.W., "Integrated \& Interactive Appropriate productive Maintenance", PhD thesis, University of Birmingham, 1996.

3. Labib, A.W., Williams, G.B. and O'Connor, R.F., "Formulation Of An Appropriate Productive Maintenance strategy Using Multiple Criteria Decision Making", Maintenance Journal, Vol. 11, No 11, April, 1996.

4. Labib, A.W., Williams, G.B. and O'Connor, R.F., "An Intelligent Decision Analysis Maintenance System: Application of AHP and Fuzzy Logic", Proceedings of The Fourth International Symposium on AHP, Vancouver, Canada, 12-16 July 1996.

5. Labib, A.W., Williams, G.B., and O'Connor, R.F., "Deriving A Maintenance Strategy Through The Application of An M.C.D.M. Methodology", Lecture Notes in Economics and Mathematical Systems, No. 448, Multiple Criteria Decision-Making, Proceedings of the $12^{\text {th }}$ Int. Conference, Germany. Springer-Verlag, 1997.

6. Labib, A. W., O'Connor, R.F. and Williams, G.B., "An Effective Maintenance System Using The Analytic Hierarchy Process", Journal of Integrated Manufacturing Systems, Volume 9 No 2, April, 1998.

7. Labib, A.W., Cutting, M.C., and Williams, G.B., "Towards A World Class Maintenance Programme", Proceedings of CIRP Int. Symposium: Advanced Design \& Manufacture In The Global Manufacturing Era, Hong Kong, August 21-22, 1997.

8. Labib, A.W., Williams, G.B. and O'Connor, R.F. "An intelligent model (system): an application of the analytic hierarchy process and a fuzzy logic controller". Journal of the Operational Research Society 49: 1-13, 1998.

9. Labib, A.W., "World class maintenance using a C.M.M.S." Journal of Quality in Maintenance Engineering, 1998.

10. De Jager P, and Bergeon R., "Managing '00: Surviving the Year 2000 Computing Crisis". John Wiley \& Sons, USA, 1997

11. Ragland B. “A Five-Step Disaster Prevention Plan". Computing McGraw-Hill, USA., 1996.

12. Murray, J.T, and Murray M.J., "The Year 2000 Computing Crisis: $A$ Millennium Date Conversion Plan". Computing Mc Graw-Hill, USA, 1996. 
13. Ulrich W.M., and Hayes, I.S., "The Year 2000 Software Systems Crisis: The Challenge of the Century". Yourdon Press Computing Series, USA. 1997.

14. Vargas, L.G., "An overview of the analytic hierarchy process and its application", European journal of operational research, 48: 1-7, 1990.

15. Saaty, T.L., "Fundamentals of Decision Making And Priority Theory With The Analytic Hierarchy Process", RWS Publications, Pittsburgh, USA, 1994.

16. Volgenant, A., and Marsman, S., "A core approach to the 0-1 equality knapsack problem". Journal of the Operational Research Society 49: 86-92, 1998.

17. Bennett, J.P., and Saaty, T.L, "Knapsack allocation of multiple resources in benefit-cost analysis by way of the analytic hierarchy process". Journal. of Mathematical Computation and Modelling 17:55$72,1993$.

18. Expert Choice Software, Expert Choice Inc. Pittsburgh, USA, 1996. 